\title{
A review on the use of sensors to monitor cattle jaw movements and behavior when grazing
}

\author{
Andriamasinoro Lalaina Herinaina Andriamandroso ${ }^{(1,2,3)^{*}}$, Jérôme Bindelle ${ }^{(3)^{*}}$, \\ Benoît Mercatoris ${ }^{(2)}$, Frédéric Lebeau ${ }^{(2)}$
}

\author{
(1) Université de Liège - Gembloux Agro-Bio Tech. TERRA. AgricultureIsLife. Passage des Déportés, 2. BE-5030 Gembloux \\ (Belgium).E-mail: alh.andriamandroso@ulg.ac.be \\ (2) Université de Liège - Gembloux Agro-Bio Tech. Agrobiochem. Precision Agriculture Unit. Passage des Déportés, 2. \\ BE-5030 Gembloux (Belgium). \\ (3) Université de Liège - Gembloux Agro-Bio Tech. Biosystems Engineering. Precision Livestock and Nutrition Unit. Passage \\ des Déportés, 2. BE-5030 Gembloux (Belgium).
}

* These authors contributed equally to this paper.

Received on April 1, 2015; accepted on May 24, 2016.

Introduction. Precision Livestock Farming (PLF) is spreading rapidly in intensive cattle farms. It is based on the monitoring of individuals using different kinds of sensors. Applied to grazing animals, PLF is mainly based on the recording of three parameters: the location, the posture and the movements of the animal. Until now, several techniques have been used to discriminate grazing and ruminating behaviors with accuracies over $90 \%$ on average, when compared to observations, providing valuable tools to improve the management of pasture and grazing animals. However, bites and jaw movements are still overlooked, even though they are of utmost importance to assess the animal grazing strategies for various pasture types and develop future techniques allowing better estimation of their intake.

Literature. The goal of this review is to explore the possibility of monitoring the individual jaw movements and the differentiation of bites in grazing animals. For this purpose, (1) the mechanisms of forage intake in cattle are explained briefly in order to understand the movements performed by the cow, especially during grazing, (2) the various sensors that have been proposed to monitor jaw movements of ruminants such as mechanical sensors (pressure sensors), acoustic sensors (microphone) and electromyography sensors are compared and (3) finally the relationship between jaw movements, biting behavior and forage intake is discussed.

Conclusions. The review clearly demonstrated the abilities of mechanical, acoustic and electromyography sensors to classify the difference types of jaw movements. However, it also indicated a wide range of accuracies and different observation windows required to reach these accuracies when compared to the observed movement. This classification purpose could lead to a better detection of more specific behavior, e.g. bite detection, and their exact location on pasture.

Keywords. Precision agriculture, livestock management, cattle, sensors, movements, forage.

Synthèse sur l'utilisation de capteurs pour le suivi des mouvements de mâchoire et du comportement de bovins au pâturage

Introduction. L'élevage de précision se répand rapidement au niveau des exploitations bovines de type intensif. Il utilise différents capteurs pour suivre chaque individu présent dans le troupeau. Pour les ruminants au pâturage, le système est basé sur l'enregistrement de trois paramètres : leur localisation, leur posture et leurs mouvements. Les techniques actuelles permettent de détecter les comportements de pâturage et de rumination avec une précision moyenne supérieure ou égale à $90 \%$, comparée aux observations. Ces techniques peuvent fournir des outils intéressants pour améliorer la gestion de la prairie et des animaux. Cependant, la caractérisation des mouvements de la mâchoire et des bouchées reste souvent négligée, sachant que ces paramètres peuvent être très importants pour évaluer les stratégies de pâturage des animaux et pour espérer estimer la quantité de fourrage ingérée.

Littérature. L'objectif de cette synthèse est de discuter des techniques utilisées pour la caractérisation et la classification des mouvements de la mâchoire ainsi que des bouchées chez les ruminants. Pour cela, (1) les mécanismes d'ingestion de fourrage des bovins sont d'abord brièvement expliqués, ensuite (2) les différents types de capteurs utilisés pour détecter les mouvements de la mâchoire, tels que les capteurs de pression, accéléromètre, microphones et capteurs électromyographiques, sont décrits et comparés, et (3) les éventuels liens entre les mouvements de la mâchoire, la bouchée et le fourrage ingéré sont discutés en se basant sur les résultats de recherche déjà effectués dans ce domaine. 
Conclusions. La conclusion de cette synthèse est que les capteurs mécaniques, acoustiques et électromyographiques ont montré leur capacité à classifier les différents types de mouvements de la mâchoire avec différentes précisions et différentes fenêtres de temps nécessaires pour cette classification. Cette classification pourrait mener à une meilleure détection de comportements plus précis telle que la détection des bouchées et leur localisation sur le parcours.

Mots-clés. Agriculture de précision, conduite d'élevage, bovins, capteurs, mouvements, fourrage.

\section{INTRODUCTION}

Sensors enable the monitoring of many physical variables. Their use in Precision Livestock Farming (PLF) has increased rapidly over the past decade for research purposes and also in on-farm applications. Unlike more traditional livestock management methods which focus on the herd, PLF is based on:

- the monitoring of variables at the individual level (Hostiou et al., 2014) and at an appropriate frequency with reliable sensors;

- the development of predictive models describing the animal's responses to environmental stimuli for each measured variable;

- the comparison of the prediction models with what is actually measured through the sensors.

The ultimate goal is to suggest managerial options to the farmer. Measuring such variables requires trade-offs between upstream data acquisition at high frequency, while preserving battery life and considering memory limits which are specific to the sensors that are used, and downstream output accuracy obtained using adequate data treatment methods.

In this respect, sensors can be used individually or in combination to track, detect, classify, manage and possibly control animal movements and behaviors. Monitoring ruminant behavior is a key to understanding how animals fulfill their requirements in pastoral systems by grazing a dynamic vegetation to achieve optimal plant production, animal forage intake and performances (Carvalho, 2013). Traditional managerial tools are limited to adjusting stocking rates and occupation times in rotational grazing, supplementing the animals and controlling concentrate intake at herd or individual level and indirect monitoring of forage intake through milk production, growth performance, or pasture disappearance (Holechek et al., 2011; Carvalho, 2013). Precision Livestock Farming opens a wide range of new perspectives in both intensive pasture and extensive rangeland management by focusing on the individual instead of the whole herd. For example, Laca (2009) proposed a system in which both animal health and plant-animal interactions are monitored by combining animal position and behavior data to remotely manage individual health and feeding.

Controlling individual animal foraging behavior on pasture means the monitoring of grazing, rumination and resting behaviors, which all together occupy $90 \%$ to $95 \%$ of the daily time budget. During the last 5 to $10 \%$, animals are busy displaying social behaviors, walking, drinking, eating supplements, etc. that might also provide interesting insights in terms of animal management (Walker et al., 2008). Focusing on feeding behavior, individual monitoring of grazing animals is based on the recording of three main parameters:

- the location of the animal: where it is in the paddock, in order to identify grazing stations;

- the posture of the animal, the static element composing a behavior such as the position of the head or the back;

- the movement of the animal, the dynamic element composing a behavior such as moving legs or jaw.

Tracking location on pasture was made possible by the large dissemination of Global Positioning System (GPS) sensors. Global Positioning System has been successfully used to detect static or dynamic unitary behaviors differentiated through changes in path speeds: foraging or grazing, resting and walking (Anderson et al., 2012). Nonetheless, accuracies of behavior classification based on GPS sensors, with sampling frequency lower than $10 \mathrm{~Hz}$, remain poor, i.e. $<80 \%$ when compared to visual observations based on time windows of 5 min each (Schlecht et al., 2004; Larson-Praplan et al., 2015). Posture analysis has been more recently developed through the use of accelerometers and based mainly on the position of the head: up or down. This information, in combination with GPS-based data, allowed discrimination between several kinds of feeding related behaviors for grazing animals with high accuracies ( $>90 \%)$. Those accuracies were obtained with a short time window of 5 to $10 \mathrm{~s}$ while the data acquisition from the GPS and the accelerometer ran between $4 \mathrm{~Hz}$ and $10 \mathrm{~Hz}$ (Dutta et al., 2015; González et al., 2015).

Finally, monitoring of cattle movements is mainly obtained using accelerometers. Through diverse analysis methods, accelerometers recording data at $10 \mathrm{~Hz}$ could be used to classify behaviors, as done for example by Mangweth et al. (2012) when they classified lame and non-lame cows using a basic statistical method, reaching an average accuracy of 91\%. Similarly, Martiskainen et al. (2009) classified multiple behaviors using a machine learning method with accuracies ranging from $29 \%$ to $86 \%$ with samples windowed for $10 \mathrm{~s}$ for all behavior classifications. 
The online detection and classification of the behaviors are essential for the development of remote and automatic monitoring of cattle on pasture. However, other components of animal movements, like jaw movements, are presently overlooked, while they are of utmost importance to assess animal grazing strategies when grazing various types of pastures and to develop new methods to better estimate their intake. Nonetheless, bite mass and subsequent intake rate are the most variable components of the feeding behavior, thus the most difficult to predict. Bite mass and intake rate are influenced by very large range with sward height, sward bulk density, botanical family and species, animal characteristics and motivation duration of the previous starvation period, grazing system, pasture allowance, concentrate and forage supplementation level, daily time of access to pasture, hour of day, etc. (Rook et al., 1994; Gibb et al., 1997; Barrett et al., 2001). Therefore recording bite mass from jaw movements seems only a dream today. Bonnet et al. (2015) recently studied the possibility of doing a continuous bite monitoring with acoustic sensors coupled to direct observation with trained observers. Combined with preliminary estimates of bite mass performed by the hand-plucking method (Bonnet et al., 2011), they could estimate bite mass with an accuracy ranging between $80 \%$ and $94 \%$, in a short-term intake rate (approximately
$10 \mathrm{~min}$ ). Although not applicable for PLF purposes, such methods suggest that combining information provided by different sensors, for example location, head position and acceleration, and jaw movements, may help overcome the everlasting challenge of intake estimation on pasture.

The main goal of this review is to assess the technologies available for the monitoring of individual jaw movements in cattle for research and PLF uses and to discuss the mechanisms of bite mass constitution and their links with jaw movements. For this purpose, we will:

- discuss the mechanisms of forage intake,

- detail various sensors that have been proposed to monitor jaw movements of ruminants,

- outline the link between jaw movements, biting behavior and forage intake, focusing mainly on cattle.

\section{MECHANISM OF FORAGE INTAKE FOR CATTLE}

Grazing is a complex combination of various movements and activities performed at different temporal and spatial scales as shown in figure 1. The single bite is the elementary component of the grazing

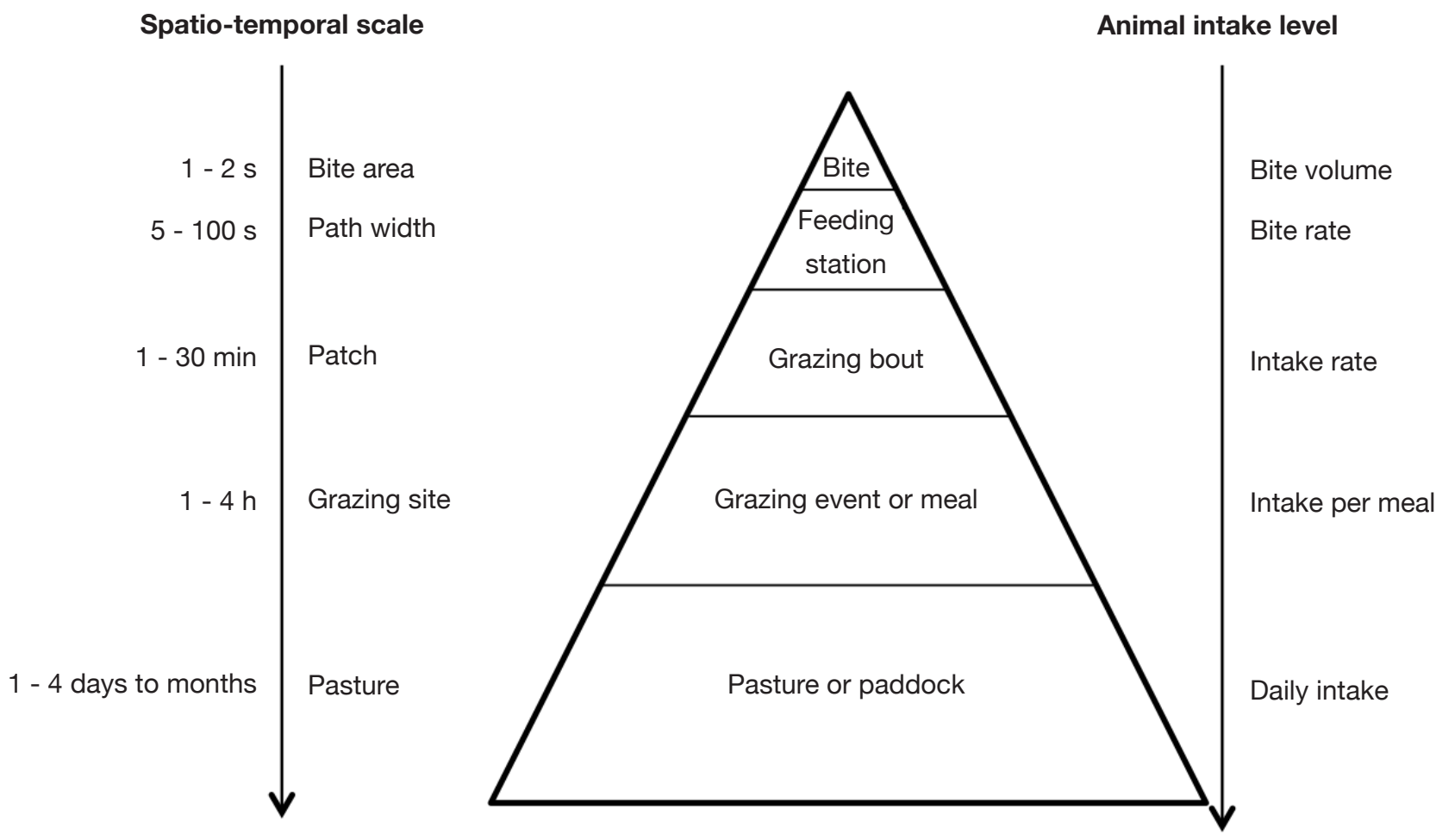

Figure 1. Spatio-temporal components of grazing behavior (adapted from Gibb, 1996; Gregorini et al., 2006; Carvalho, 2013) - Composantes spatio-temporelles du comportement de pâturage (adapté de Gibb, 1996 ; Gregorini et al., 2006 ; Carvalho, 2013). 
process (Ungar et al., 2006a; Carvalho, 2013). Its frequency ranges from 0.75 to 1.2 bites per second and its size is mainly determined by the mouth of the animal as well as some vegetation characteristics such as sward height, tensile strength and density (Griffiths et al., 2003; Oudshoorn et al., 2013a; Oudshoorn et al., 2013b). Several bites performed in a row by an animal on a single feeding station without interruption compose a grazing bout (Gibb, 1996) that will cover a few square meters and last between 10 to 100 seconds (Andriamandroso et al., 2015). Several grazing bouts are performed during each grazing event or meal (Gibb, 1996) that occurs each day for several minutes to hours during which a significant portion of the paddock is explored. Finally, the paddock is occupied for some days to several months and covers an area that is usually over 1 ha. Only the two highest levels in figure 1, i.e. grazing event and paddock, are discussed in most of research on the detection and classification of grazing behavior.

A detailed observation of cattle movements at individual bite level (Figure 2) shows that foraging requires mainly jaw and accessorily tongue movements that can be broken down into four phases. Firstly, during prehension, cows surround a bunch of grass using their tongue and lips (Frames 1 and 6, Figure 2) and take it into their mouth (Frame 11, Figure 2). Then the grass is grabbed between the lower jaw and the gum (Frame 16, Figure 2) and it is finally cut with a sudden movement of the lower jaw usually accompanied by a movement of the whole head to perform the proper defoliation (Frames 21 and 25, Figure 2). This abrupt head movement is marked by an upward thrust of the mouth visible by the increase in distance between the mouth and the baseline and is usually considered as the actual bite (Gibb, 1996) (Figure 2). The whole forage intake is ended by chewing and swallowing the plant biomass (Vallentine, 2000).
Rumination jaw movements are more quiet and regular. They are composed of a cyclic process which begins with the regurgitation of a rumino-reticular bolus followed by semi-circular jaw movements with a specific frequency of $1.06 \pm 0.06 \mathrm{bites} \cdot \mathrm{s}^{-1}$ during mastication and ends with the deglutition. Deglutition is described as a pause between two bouts of mastication while the mastication cycle lasts between $15 \mathrm{~s}$ and $60 \mathrm{~s}$ (Andriamandroso et al., 2014).

In order to detect bites, various techniques have been developed to monitor jaw movements of ruminants (Figure 3). Before the early 1980's, tools for counting jaw movements were strictly mechanical. Jaw movements were recorded on paper rolls or disks (e.g. Balch, 1958) or counted via built-in electrical circuits used as recorders (e.g. Stobbs et al., 1972). However such devices cannot be properly considered as sensors since a sensor is a device that detects events or measures changes in a physical property such as light, force and sound in its environment and transforms them into a usable signal, usually an electrical output, for further analysis (Kenny, 2005). According to a literature survey (Figure 3) pressure and microphone sensors are the most used sensors for monitoring cattle jaw movements with 35 and 14 references, respectively. While only 4 references mention acceleration sensors, their use is rising rapidly. Electromyography sensors are also sometimes cited ( 2 references), while the two last references compared different types of sensors.

\section{USE OF SENSORS FOR JAW MOVEMENTS DETECTION AND QUANTIFICATION IN CATTLE}

Devices dedicated for jaw movements detection can be classified in five groups (Figure 3):

- jaw switches, where a switch is activated at each jaw movement;

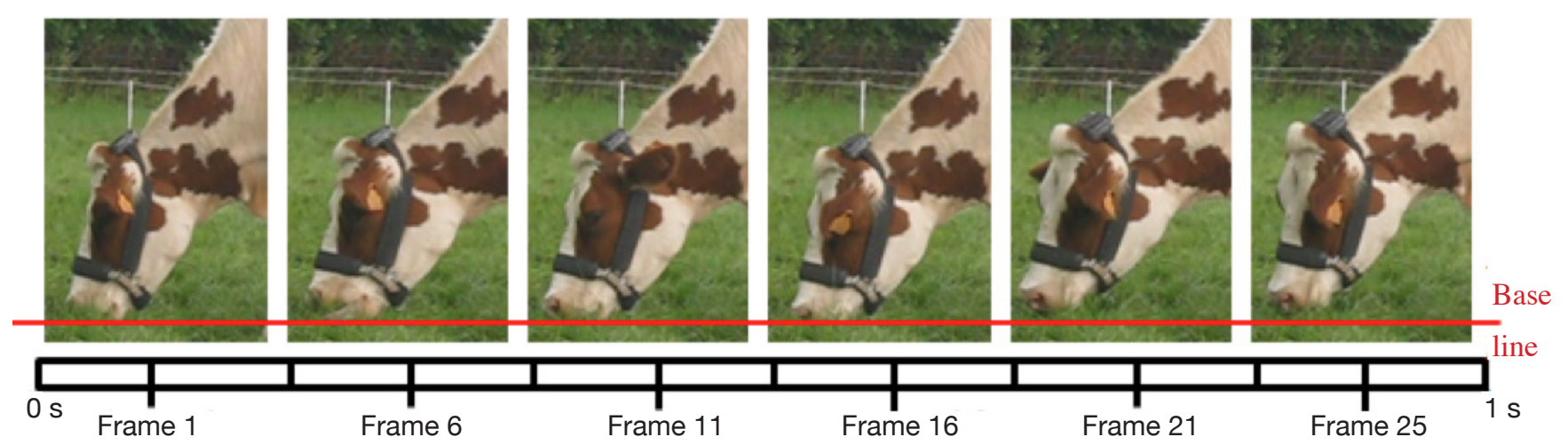

Figure 2. Visualization of cattle mouth movements (25 frames per second video) - Mouvements effectués par la vache lors du pâturage (photographies tirées d'une vidéo à 25 images par seconde). 


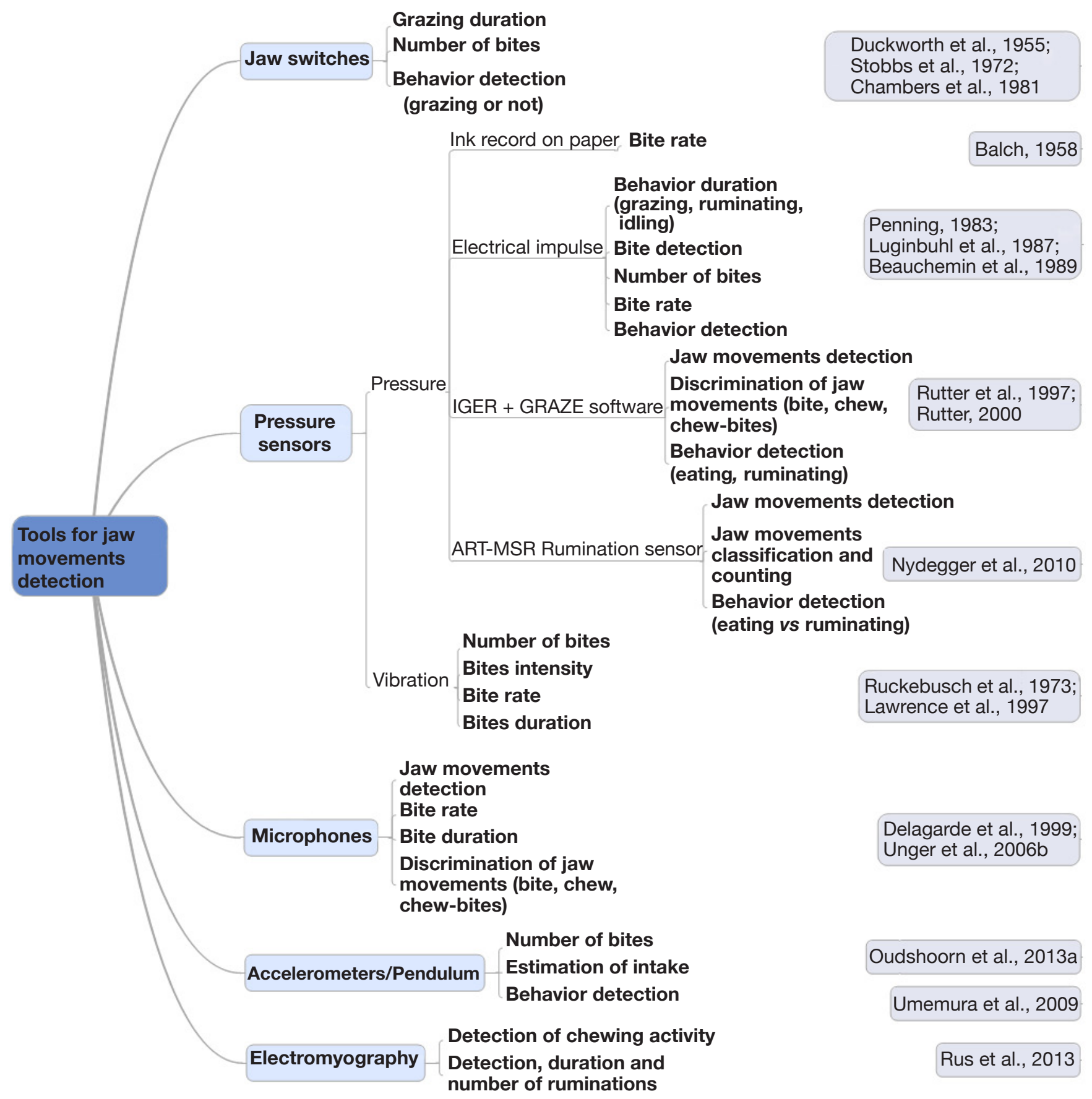

Figure 3. Principal tools used to characterize jaw movements of cattle: references used in this figure came from research in Scopus (www.scopus.com, Elsevier, The Netherlands, 31/07/2015) using combination of three groups of keywords (total of 57 references): a: "bite" OR "chewing" OR "mastication" OR "jaw movements" OR "jaw"; b: "cattle" OR "cows" OR "heifer" OR "heifers" OR "calves"; c: "sensor" OR "electronic device" OR "tool" - Principaux outils utilisés pour caractériser les mouvements de mâchoire des vaches. Les références utilisées dans cette figure sont issues de recherches bibliographiques effectuées dans Scopus (www.scopus.com, Elsevier, The Netherlands, 31/07/2015) selon les groupes de mots-clés suivants (total : 57 références) : $a:$ : bite » $\mathrm{OR}$ « chewing » $\mathrm{OR}$ « mastication» $\mathrm{OR}$ « jaw movements » $\mathrm{OR}$ « jaw »; $b:$ « cattle » $\mathrm{OR}$

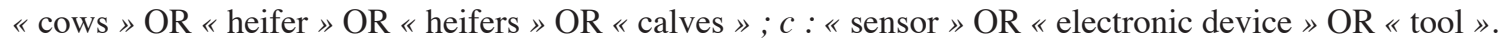


- pressure sensors, where a jaw movement corresponds to a change in pressure or length in a tube around the nose;

- microphones, where sound patterns allow jaw movement detection;

- accelerometers, to detect movements operated during a jaw movement;

- electromyography, transducing a jaw movement to an electrical signal from the movement of the muscle.

In the following section, only the last four sensors will be discussed, because jaw switches are not actual sensors as previously explained, since the collected information is printed directly and is not transformed into a digital or electrical signal output (e.g. Balch, 1958).

\subsection{Pressure sensors}

The use of pressure sensors in bite monitoring began with the pioneering works of Penning (1983). His instrument was composed of a halter fitted with a silicon noseband connected to two electrodes. When the noseband stretched from a jaw movement, it changed the electrical resistance between the electrodes placed at both ends of the tube. This induced a change in voltage which produced a signal which was proportional to the extent of the jaw movement and waving (Harman, 2005). It was used successfully to differentiate grazing and ruminating behaviors and to measure time spent grazing, ruminating and idling, achieving a 95\% agreement with visual observations over a time window of 3 min (Penning, 1983). Several variations of the method exist, including initially the use of a rubber tube or balloon placed just under the lower jaw (Luginbuhl et al., 1987) but enhanced later as a tube encircling the nose (Penning, 1983; Rutter et al., 1997; Nydegger et al., 2010) or under the jaw (Dado et al., 1993).

Building on this technology, two systems were developed which were used exclusively in research and not applied in PLF (Figure 4). The IGER Behaviour Recorder (Institute of Grassland and Environmental Research, Okehampton, UK, Rutter et al., 1997) and the ART-MSR pressure sensor (Agroscope Reckenholz-Tänikon ART Research institute, Modular Signal Recorder MSR145, MSR Electronics GmbH, Switzerland, Nydegger et al., 2010) were designed for pasture and for stable use respectively. Both devices are able to make a 24-hours continuous data recording, with a maximum of $40 \mathrm{~h}$ for ART-MSR (Nydegger et al., 2010). The IGER Behaviour Recorder consists of a noseband and an electronic interface including a rechargeable battery connected to a computer board allowing a memory card to record, analyze and store data at $20 \mathrm{~Hz}$. A jaw movement is recognized as a pressure peak through the transmission of the movement to the halter and the change in the tube pressure. The software installed on the computer board (Rutter, 2000) is able to classify jaw movements (bites or chews), identify jaw movement bouts and determine the behavior associated with each bout with defined thresholds based on the analysis of the peaks shape. Peaks are considered as bites when they are a combination of a major long peak followed by a smaller sub-peak or a non-symmetrical peak in the absence of the sub-peak (Nadin et al., 2012). Conversely, a chew contains only one peak of symmetrical shape (Champion et al., 1997). The detection accuracy reaches an overall concordance of $91 \%$ with $95 \%$ for eating and $93 \%$ for ruminating when compared to the observations on a 5-min time window-basis with a maximal sampling rate of $20 \mathrm{~Hz}$

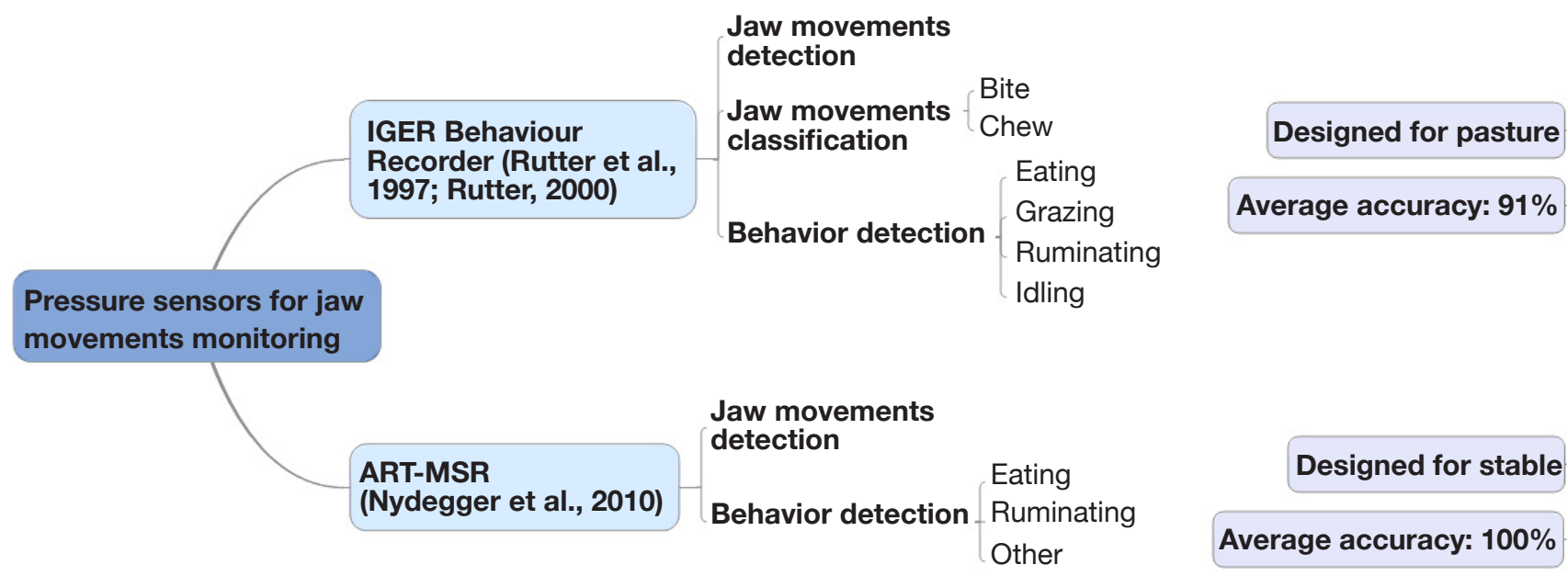

Figure 4. Comparison of the two most-used pressure sensors to monitor jaw movements of cattle - Comparaison des deux capteurs de pression les plus utilisés pour le monitoring des mouvements de la mâchoire des vaches. 
(Rutter et al., 1997). Those accuracies decreased for cattle grazing a tropical pasture and confronted with more heterogeneous grazing conditions, as it was difficult to clearly differentiate biting from other jaw movements (Nadin et al., 2012).

Several studies (12 references) used the IGER Behaviour Recorder to investigate the effect of different factors such as the time of grazing (Abrahamse et al., 2009), the sward height (Gibb et al., 1999; Fonseca et al., 2013), the physiological state of the animal (Gibb et al., 1999) or the milking frequency (O'Driscoll et al., 2010) on grazing behavior or on grazing intake. The latest study was done by Fonseca et al. (2013) who used grazing bites detected and counted by the IGER Behaviour Recorder to estimate bite mass and bite rate for determining the effect of sward height and level of herbage depletion on these bite features.

In the ART-MSR system (Nydegger et al., 2010), the tube encircling the mouth is filled with oil and the sensor records the pressure change when the jaw is moving. When the cow opens her mouth, an increase in pressure alters the electrical resistance, resulting in a signal in the sensor corresponding to one chew (Braun et al., 2014). Apart from the jaw movements features as described for the IGER Behaviour Recorder, it is also possible to estimate the feed intake from the number of chews and duration of eating time with reasonable correlation coefficients $\left(\mathrm{R}^{2}=0.6\right.$ to 0.9$)$ (Pahl et al., 2015). Accuracies in detecting eating and ruminating activities approached $100 \%$, while counting jaw movements performed during each behavior gave disagreement rates of $12 \%$ and $0.24 \%$ respectively compared to observations performed over $5 \mathrm{~min}$ (Nydegger et al., 2010). Thus, this tool is more accurate when counting ruminating jaw movements, probably due to the regular pattern of this behavior compared to eating.

To conclude, pressure sensors derive their power in detecting jaw movements by identifying patterns that are different during eating and rumination. The silicon tube encircles the nose as a normal halter, so it does not alter the normal behavior of the cow. Misclassifications in this method usually arise from practical considerations. Variation in the tightening of the halter on individual animals can generate different pressure values, modifying discrimination thresholds. The analysis of the output wave signal based on the peak detection is compromised if the halter is mounted too tightly or too loosely (Nydegger et al., 2010). Moreover, automated transmission of data is not yet developed.

\subsection{Acoustic monitoring of jaw movements using microphones}

The miniaturization and accessibility of different kinds of sensors increased the use of microphones for the detection and characterization of cattle jaw movements. In a microphone, sounds are going through a flexible diaphragm and cause vibrations. The output electrical signal is proportional to the intensity of these vibrations as well as their frequencies.

Microphones used for recording jaw sounds of a grazing ruminant can be used to discriminate bites or chews. This allows the classification between grazing or ruminating behavior to be achieved over time with a succession of bites or chews (Navon et al., 2013; Benvenutti et al., 2015).

Acoustic analysis allows differentiation of three types of jaw movements: chew, bite and chew-bite. Bite refers to a ripping sound while chew refers to a grinding sound, easing the differentiation between these two types of jaw movements. Chew-bite corresponds to an intermediate between chew and bite sound, i.e. during this jaw movement the herbage already in the mouth is chewed and simultaneously a new mouthful of herbage is severed; these two movements are performed within a single jaw movement (Ungar et al., 2006b).

Methods using sound recordings for jaw movements classification differ according to the location of the microphone, the processing of the acoustic signal and the aim of classification (Table 1). Some methods are only able to detect jaw movements. For example, based on 10 min of grazing session recorded by a camera, the simple detection of jaw movements using a machine learning technique reaches an accuracy of $94 \%$ when compared to the aural analysis of sounds by a trained operator (Navon et al., 2013). The machine learning algorithm uses four properties of the signal pattern: the shape to determine jaw movements interval, the intensity of each jaw movement represented by a peak in the time domain, the duration and their integration in a sequence of behavior (Navon et al., 2013). Clapham et al. (2011) used similar parameters (frequency, intensity, duration and time between events) calculated during sound segments of 1 to 5 min to detect and analyze bites, reaching an overall behavior classification accuracy of $94 \%$. Using a discriminant function, bite and chew could also be differentiated with an accuracy of 94\% (Clapham et al., 2011). The discriminant analysis is based here on three parameters determined from the signal pattern of the sound produced during biting and chewing inside a $1 \mathrm{kHz}$ sound window: peak frequency, peak intensity, average intensity and their duration (Laca et al., 2000). Finally, detection and classification of the three types of jaw movements (bite, chew and chew-bite) are possible using the Hidden Markov model. This model estimates sequences of bites or chews or chewbites, called hidden states, which are not observable directly, using their acoustic spectrum characteristics i.e. the energy produced, in decibels, by each sound. Using different frame lengths (20 to 80 milliseconds) 
Andriamandroso A.L.H., Bindelle J. et al.

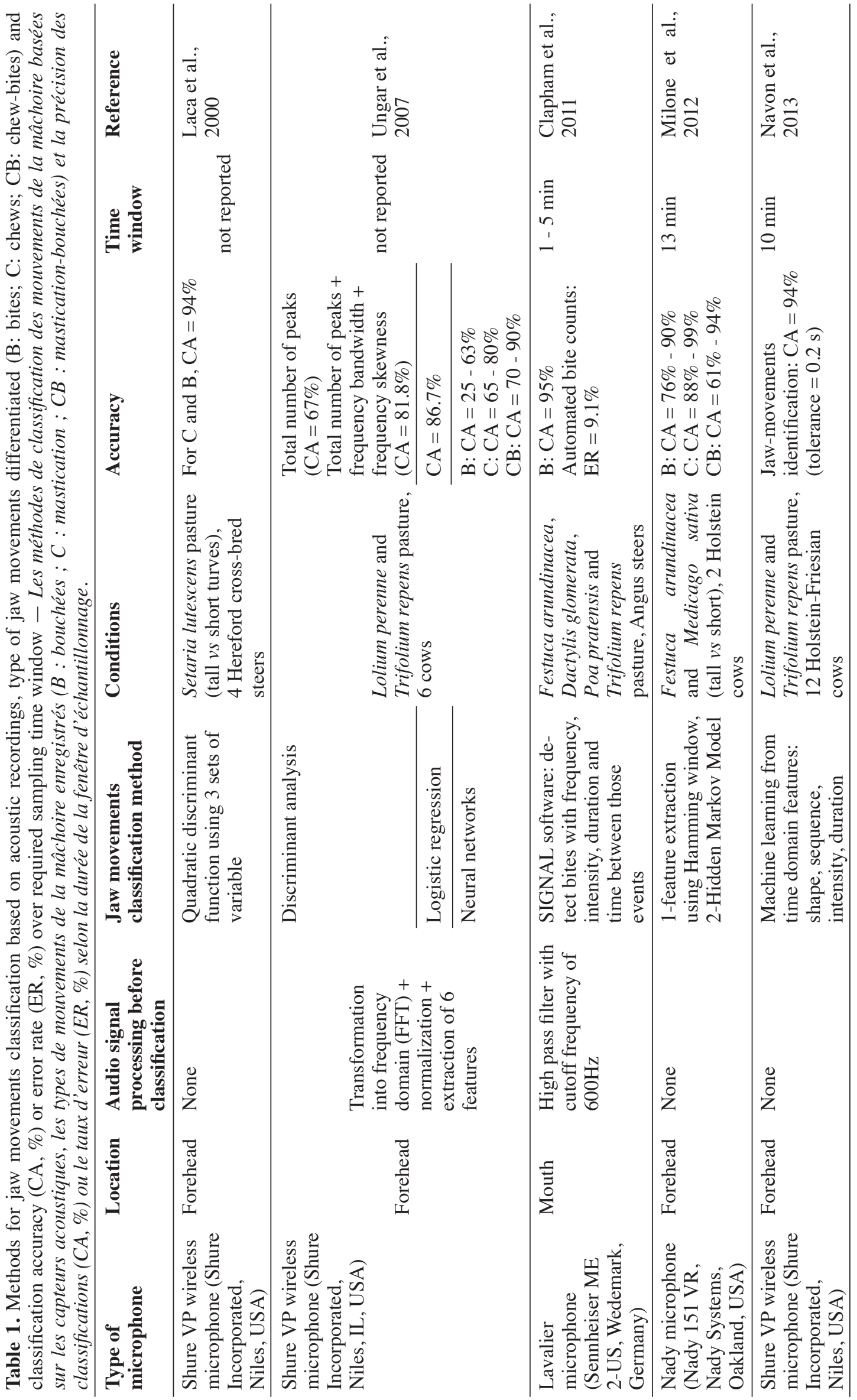


correct classification of those three jaw movement types ranged between $61 \%$ and $99 \%$ and is influenced by the pasture type and grass height (Milone et al., 2012). Using discriminant analysis, logistic regression and neural networks as classification methodologies yielded $67 \%$ to $82 \%, 87 \%$ and $25 \%$ to $90 \%$ of correct classifications respectively, while the time window used in the calculations was not reported (Ungar et al., 2007).

In addition, Nadin et al. (2012) showed no significant differences between visual observations and microphone-based detection methods in studies demonstrating the performance of acoustic sensors to monitor grazing jaw movements of cattle. Moreover, since grazing corresponds to a succession of bites and chews with accessorily chew-bites and rumination corresponds to a succession of chews, it is also possible to differentiate those behaviors using microphones (Navon et al., 2013).

To summarize, microphone-based methods reach good accuracy for jaw movements detection. In addition, they are able to differentiate three different kinds of jaw movements: two visible movements corresponding to chew and bite, and one intermediate difficult to detect visually (chew-bite). However, outdoor applications are disturbed by environmental noises, so extending sound recording and interpretation techniques acquired under ideal experimental conditions to an on-farm level tool recording and analyzing sounds automatically for PLF applications still requires significant development.

\subsection{Acceleration sensors}

An accelerometer is an electronic sensor transforming physical acceleration from motion or gravity into waveform voltage signal output. It can measure both static acceleration due to gravity, the low-frequency component of the acceleration and the dynamic acceleration due to movements imprinted by the animal (Almeida et al., 2013; Brown et al., 2013).

Despite the depth of literature surveyed, only four references used this type of sensor to identify and classify jaw movements, among which three described different methods of classification. In stables, Tani et al. (2013) coupled a 1-axis accelerometer to a microphone to classify cattle chewing activities by matching 1 minute segment waveform patterns to observed eating and ruminating behaviors. Intake chewing activities were highly distinguished at $90 \%$, reaching 99\% when the sensor was attached to the cow's horn.

On pasture, a 3-axis accelerometer was used by Oudshoorn et al. (2013b) to record cow bites. A visualization of recorded signals from the three individual orthogonal axes $(x, y, z)$ was done first, in order to determine which one matched best with the observed bites. To determine each bite, a series of thresholds were tested to determine the peak which had the best correlation to the observation. The average correlation coefficient was 0.65 indicating the difficulty to count bites using an accelerometer this way. Finally, Umemura et al. (2009) modified a pedometer into a pendulum under the lower jaw to monitor cattle jaw movements. The data could be wirelessly downloaded from the sensor which had a lifespan of one year. This system was able to count jaw movements with an accuracy of $90 \%$ compared with manual counts over 10 min segments. This bite count was correlated with a coefficient of 0.7 to pasture disappearance estimated indirectly by a rising plate meter.

Accelerometer sensors thus provided interesting options to automatically count cattle jaw movements. As for sound sensors, interference may be present in the signal recorded by the sensor. Bites are the result of jaw and head movements while chew imprints mostly jaw movements. The sensitivity of accelerometers could provide undesirable signals during recording sessions due to ear movements or sudden head turns to drive flies or other insects away. Thus, a pre-processing of the signal is probably required to isolate the signal relative to the jaw movements in order to consider this method for actual PLF uses on farms. In terms of material, the use of an inertial measurement unit (IMU) which is a combination of accelerometers, gyroscope, magnetometer and location sensors might offer a real advantage knowing that all these variables can be recorded simultaneously at a high sampling frequency $(100 \mathrm{~Hz})$. For example, Andriamandroso et al. (2015) used smartphone IMUs to count the number of bites through frequency pattern of 1-axis acceleration data. As for pressure sensors, if the accelerometer is mounted in a halter, the tightening also plays an important role in the transmission of the movement to the sensor.

\subsection{System based on electromyography}

While the noseband pressure sensor quantifies changes in tube pressure and translates it into an electrical impulse, electromyographic sensors quantify the electrical potential of masticatory muscles during contractions (Rus et al., 2013). Two electrodes are fixed on a halter and measure electrical signals occurring during a jaw movement with a contraction of the Masseter muscle. This sensor, coupled to a 3-axis accelerometer and a wireless transmission of data in real time, constitutes the DairyCheck sensor (Rus et al., 2013). This system is able to detect ruminating and feeding behavior on the basis of the regularity and irregularity of signal pattern respectively. The DairyCheck system yielded an overall concordance of $87 \%$ compared to visual observations over 1 minute, when detecting feeding time and rumination time (Büchel et al., 2014). 
Finally, when the different above-mentioned techniques are compared, noseband pressure sensors and microphones are best able to detect jaw movements with high accuracy (over 94\%) and differentiate biting and chewing jaw movements with fair accuracy $(61 \%$ to $95 \%$ for microphone) (Table 2). Accelerometers can identify jaw movements with less than $90 \%$ of accuracy but discrimination of the different types of jaw movements is not mentioned yet. Authors using the electromyography method did not give any information about the accuracy of the detection of specific jaw movements.

\section{ESTIMATION OF GRAZING INTAKE THROUGH BITES QUANTIFICATION}

For many years, various methods have been used to quantify forage intake of grazing herbivores, including the measurement of pasture biomass before and after grazing, changes in animal bodyweight, digestive markers, or fecal near-infrared reflectance spectroscopy (reviewed by Decruyenaere et al., 2009) (Figure 5).
Among these techniques, animal behavior can also be used as a measurement of grazing intake by combining grazing duration, biting rate and bite mass. Knowing that a bite is the elementary and indivisible unit of the whole grazing process, this technique stresses the need to properly quantify bites, to estimate the intake along with the mass of each individual bite or their average mass.

This method is based on the determination of bite mass (quantity, in grams, of grass taken in each bite) and bite rate (number of bites per minute) as per the following formula (Vallentine, 2000):

Forage intake $\left(\mathrm{g} \cdot\right.$ day $\left.^{-1}\right)=$ Bite mass $\left(\mathrm{g} \cdot \mathrm{bite}^{-1}\right) \mathrm{x}$ Bite rate $\left(\right.$ bite $\left.\cdot \min ^{-1}\right)$ x Grazing activity duration $\left(\min \cdot\right.$ day $\left.^{-1}\right)$

To efficiently use this formula, accurate detections of grazing behavior and individual bites are essential. As already mentioned, several sensors are able to quantify these parameters with various accuracies. Oudshoorn et al. (2013a) correlated intake for grazing cattle from grazing time estimated by an accelerometer and bite frequency with a prediction precision of

Table 2. Comparison of different types of sensors to detect and classify jaw movements - Comparaison des différents types de capteurs utilisés pour détecter et classifier les mouvements de la mâchoire.

\begin{tabular}{|c|c|c|c|c|}
\hline Type of sensor & $\begin{array}{l}\text { Jaw movements } \\
\text { detection accuracy }^{1}(\%)\end{array}$ & $\begin{array}{l}\text { Jaw movements } \\
\text { classification } \\
\text { (accuracy }{ }^{1} \text { in \%) }\end{array}$ & $\begin{array}{l}\text { Required sampling } \\
\text { time window (min) }\end{array}$ & References \\
\hline $\begin{array}{l}\text { Noseband pressure } \\
\text { sensors }\end{array}$ & $91-95$ & $\begin{array}{l}\text { Bite } \\
\text { Chew }\end{array}$ & $5 \mathrm{~min}$ & $\begin{array}{l}\text { Rutter et al, 1997; } \\
\text { Nydegger et al., } 2010\end{array}$ \\
\hline Microphones & $94-95$ & $\begin{array}{l}\text { Bite }(76-95) \\
\text { Chew }(88-94) \\
\text { Chew-bite }(61-94)\end{array}$ & $1-13 \min$ & $\begin{array}{l}\text { Ungar et al., 2007; } \\
\text { Clapham et al., 2011; } \\
\text { Milone et al., } 2012\end{array}$ \\
\hline Accelerometers & $65-90$ & (data not provided) & $10 \mathrm{~min}$ & Oudshoorn et al., 2013a \\
\hline
\end{tabular}

${ }^{1}$ : Comparison with visual observations - comparaison par observations visuelles.

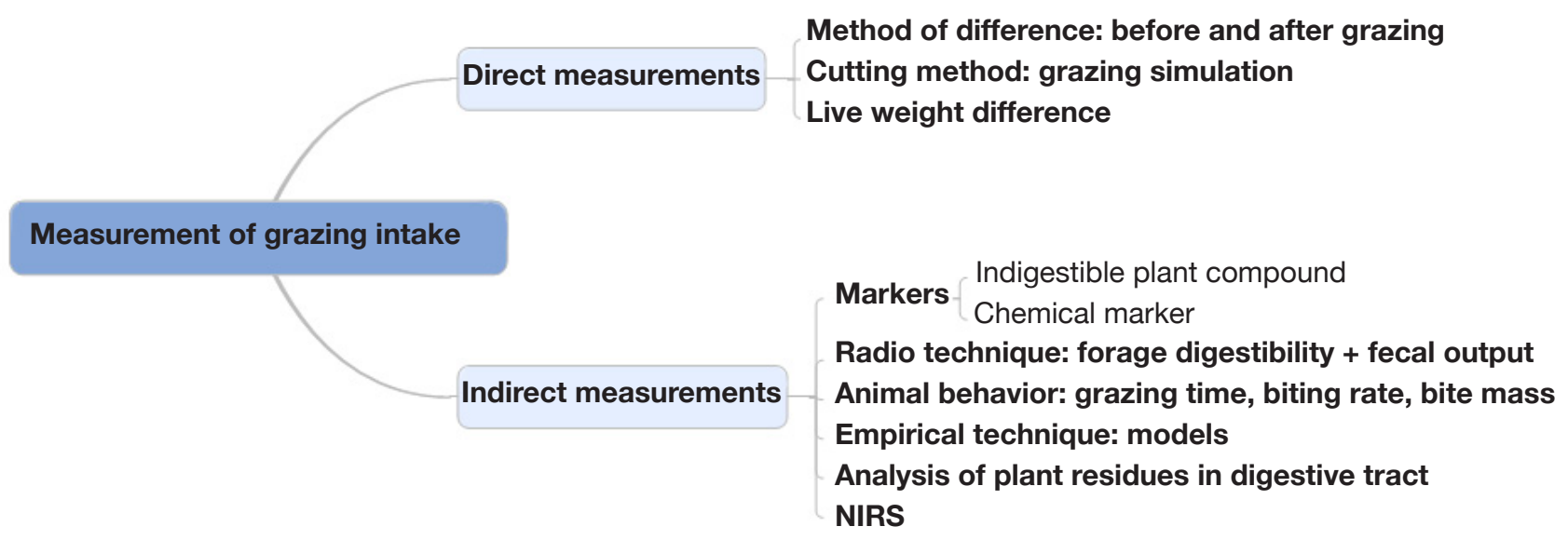

Figure 5. List of techniques for grazing intake measurement (from Decruyenaere et al., 2009) - Liste des techniques utilisées pour la mesure de l'ingestion lors du pâturage (selon Decruyenaere et al., 2009). 
less than $1.4 \mathrm{~kg}$ of dry matter per cow per day. In this experiment, grass intake was initially measured using an indigestible marker and the difference in net energy balance between energies offered by the grass and required for animal needs. This paper shows that prediction of intake from grazing behavior and bites counts is still beyond reach due to the lack of accurate bite mass estimation. Indeed, beyond bite rate, forage intake of grazing animals depends on pasture characteristics (sward height and bulk density) as expressed by the bite mass formula (Carvalho et al., 2015):

Bite mass $\left(\mathrm{g} \cdot \mathrm{bite}^{-1}\right)=$ Bite area $\left(\mathrm{cm}^{2}\right) \mathrm{x}$ Bite depth $(\mathrm{cm}) \times$ Bulk density $\left(\mathrm{g} \cdot \mathrm{m}^{-3}\right)$

In this formula, the bulk density and the bite area are calculated from empirical models using, sward height and relative bite depth (sward height/2), tiller density and forage biomass per area unit, and the size of the dental arcade. Such predictive models yield acceptable bite mass estimates in short-term experiments with very homogenous vegetation characteristics (Carvalho et al., 2015), but fail in more complex vegetation units. Until now, the best method available remains hand-plucking. It simulates a bite by mimicking grass prehension by hand and bite mass estimation accuracies can be as high as $95 \%$ for cows and goats with trained operators. This accuracy corresponded to the correlation between the amount of grass taken by the animal per bite and those plucked manually (Bonnet et al., 2011). While this method seems useful to calibrate bite masses for intake measurements for research purposes, it is timeconsuming and no sensors can perform a similar task, hence it seems useless from a PLF perspective.

Therefore, monitoring intake in grazing ruminants using PLF approaches is still out of reach. Nonetheless, from a research perspective, the bite mass formula provides interesting directions for future research on the quantification of bite mass using a combination of promising technologies such as:

- accurate monitoring of the pasture with for example distance meters and/or time-of-flight cameras,

- animal positioning with wifi triangulation or centimeter-accurate GPS,

- rigid body attitude estimation from accelerometer data to reconstruct head movement,

- jaw monitoring using sensor-based technologies described in this paper.

\section{CONCLUSIONS}

Most sensors mentioned in this review were primarily designed for research. Although some sensors such as accelerometers (e.g. SensOor ${ }^{\circledR}$, CowManager,
Utrecht, The Netherlands) are already used for behavior classification in farm situations, there use as on farm tools for jaw movements monitoring of grazing animals still requires significant hard- and software developments, especially regarding the automation process and real-time data acquisition, as well as ease of installation and use. For example, whether based on mechanical (pressure or acceleration), electrical, or acoustic signals, most sensors require the use of a halter, and the way it is mounted is extremely important in the recording of jaw movements. A pre-processing of the signal may also be required to eliminate existing noises around the animal or during the movement. Combining different sensors, for example accelerometers to microphones, may be a solution for a better monitoring of bites. Dedicated signal processing also requires significant development. For example, using frequency domain signal processing approaches on acceleration data might provide useful progress. Accuracies mentioned in this document were obtained using short time windows and different calculation methods which could affect the percentage values. Longer time step should be considered to cover one or several days in order to show if the detection accuracy would change significantly or not. Finally, PLF requires the system to be robust and adaptable to a wide range of situations. Most techniques presented here were applied under strict controlled conditions for research and their implementation in the farms would also require some ability for auto-calibration of the device or tools to overcome differences in individual physiological states, morphologies or grazing conditions according to the season and pasture.

\section{Acknowledgements}

This review is involved in a research funded by the CARE AgricultureIsLife (TERRA Research Unit, Gembloux AgroBio Tech, Université de Liège).

The authors specially acknowledge Jeffrey Peter Corfield (Corfield Consultants, Australia) for corrections and suggestions he gave to our review.

\section{Bibliography}

Abrahamse P.A., Tamminga S. \& Dijkstra J., 2009. Effect of daily movement of dairy cattle to fresh grass in morning or afternoon on intake, grazing behaviour, rumen fermentation and milk production. J. Agric. Sci., 147, 721-730.

Almeida P.R. et al., 2013. Testing a 3-axis accelerometer acoustic transmitter (AccelTag) on the Lusitanian toadfish. J. Exp. Mar. Biol. Ecol., 449, 230-238.

Anderson D.M. et al., 2012. Characterising the spatial and temporal activities of free-ranging cows from GPS data. Rangeland J., 34, 149-161. 
Andriamandroso A.L.H., Lebeau F. \& Bindelle J., 2014. Accurate monitoring of the rumination behaviour of cattle using IMU signals from a mobile device. In: Hopkins A. et al., 2014. Proceedings of the $25^{\text {th }}$ General meeting of the European Grassland Federation, EGF at 50: the future of European grasslands, 7-11 September 2014, Aberystwyth, Wales.

Andriamandroso A.L.H., Lebeau F. \& Bindelle J., 2015. Changes in biting characteristics recorded using the inertial measurement unit of a smartphone reflect differences in sward attributes. In: Guarino M. \& Berckmans D., 2015. Proceedings of the $7^{\text {th }}$ European conference on Precision Livestock Farming, Precision Livestock Farming '15, 15-18 September 2015, Milan, Italy, 283-289.

Balch C.C., 1958. Observations on the act of eating in cattle. Brit. J. Nutr., 12(3), 330-345.

Barrett P.D., Laidlaw A.S., Mayne C.S. \& Christie H., 2001. Pattern of herbage intake rate and bite dimensions of rotationally grazed dairy cows as sward height declines. Grass Forage Sci., 56, 362-373.

Beauchemin K.A., Zelin S., Genner D. \& BuchananSmith J.G., 1989. An automatic system for quantification of eating and ruminating activities of dairy cattle housed in stalls. J. Dairy Sci., 72, 2746-2759.

Benvenutti M.A. et al., 2015. Defoliation patterns and their implications for the management of vegetative tropical pastures to control intake and diet quality by cattle. Grass Forage Sci., doi: 10.1111/gfs.12186

Bonnet O.J.F. et al., 2011. Is hand plucking an accurate method of estimating bite mass and instantaneous intake of grazing herbivores? Rangeland Ecol. Manage., 64(4), 366-374.

Bonnet O.J.F. et al., 2015. Continuous bite monitoring: a method to assess the foraging dynamics of herbivores in natural grazing conditions. Anim. Prod. Sci., 55, 339-349.

Braun U., Tschoner T. \& Hässig M., 2014. Evaluation of eating and rumination behaviour using a noseband pressure sensor in cows during the peripartum period. BMC Vet. Res., 10, 195.

Brown D.D. et al., 2013. Observing the unwatchable through acceleration logging of animal behavior. Anim. Biotelem., 1, 1-16.

Büchel S. \& Sundrum A., 2014. Technical note: evaluation of a new system for measuring feeding behavior of dairy cows. Comput. Electron. Agric., 108, 12-16.

Carvalho P.C. de F., 2013. Harry Stobbs memorial lecture: can grazing behavior support innovations in grassland management ? Trop. Grasslands, 1, 137-155.

Carvalho P.C. de F. et al., 2015. Can animal performance be predicted from short-term grazing processes? Anim. Prod. Sci., 55, 319-327.

Chambers A.R.M., Hodgson J. \& Milne J.A., 1981. The development and use of equipment for the automatic recording of ingestive behaviour in sheep and cattle. Grass Forage Sci., 36, 97-105.
Champion R.A., $\quad$ Rutter S.M. \& Orr R.J., 1997. Distinguishing bites and chews in recordings of the grazing jaw movements of cattle. In: Proceedings of the $5^{\text {th }}$ British Grassland Society, BGS Research Meeting, September 1997, Seale Hayne, United Kingdom, 171172.

Clapham W.M., Fedders J.M., Beeman K. \& Neel J.P.S., 2011. Acoustic monitoring system to quantify ingestive behavior of free-grazing cattle. Comput. Electron. Agric., 76(1), 96-104.

Dado R.G. \& Allen M.S., 1993. Continuous computer acquisition of feed and water intakes, chewing, reticular motility, and ruminal pH of cattle. J. Anim. Sci., 76, 1589-1600.

Decruyenaere V., Buldgen A. \& Stilmant D., 2009. Factors affecting intake by grazing ruminants and related quantification methods: a review. Biotechnol. Agron. Soc. Environ., 13(4), 559-573.

Delagarde R., Caudal J.P. \& Peyraud J.L., 1999. Development of an automatic bitemeter for grazing cattle. Ann. Zootec., 48, 329-339.

Duckworth J.E. \& Shirlaw D.W., 1955. The development of an apparatus to record the jaw movements of cattle. $\mathrm{Br}$. J. Anim. Behav., 3(2), 56-60.

Dutta R. et al., 2015. Dynamic cattle behavioural classification using supervised ensemble classifiers. Comput. Electron. Agric., 111, 18-28.

Fonseca L. et al., 2013. Effect of sward surface height and level of herbage depletion on bite features of cattle grazing Sorghum bicolor swards. J. Anim. Sci., 91, 43574365.

Gibb M.J., 1996. Animal grazing/intake terminology and definitions. In: Proceedings of pasture ecology and animal intake workshop for concerted action AIR3CT93-0947, 24-25 September 1996, Dublin, Ireland, 20-35.

Gibb M.J., Huckle C.A., Nuthall R. \& Rook A.J., 1997. Effect of sward surface height on intake and grazing behaviour by lactating Holstein Friesian cows. Grass Forage Sci., 52, 309-321

Gibb M.J., Huckle C.A., Nuthall R. \& Rook A.J., 1999. The effect of physiological state (lactating or dry) and sward surface height on grazing behaviour and intake by dairy cows. Appl. Anim. Behav. Sci., 63(4), 269-287.

Gregorini P., Tamminga S. \& Gunter S.A., 2006. Review: behavior and daily grazing patterns of cattle. Prof. Anim. Sci., 22, 201-209.

Griffiths W.M. \& Gordon I.J., 2003. Sward structural resistance and biting effort in grazing ruminants. Anim. Res., 52, 145-160.

Harman G., 2005. Pressure sensors. In: Wilson J.S., ed. Sensor technology handbook. Amsterdam, The Netherlands: Elsevier, 411-456.

Holechek J.L., Pieper R.D. \& Herbel C.H., 2011. Range management. Principles and practices. $6^{\text {th }}$ ed. Boston, USA: Prentice Hall. 
Hostiou N. et al., 2014. L'élevage de précision : quelles conséquences pour le travail des éleveurs ? INRA Prod. Anim., 27(2), 113-122.

Kenny T., 2005. Sensor fundamentals. In: Wilson J.S., ed. Sensor technology handbook. Amsterdam, The Netherlands: Elsevier, 1-20.

Laca E.A., 2009. Precision livestock production: tools and concepts. Rev. Bras. Zootec., 38, 123-132.

Laca E.A. \& DeVries M.F.W., 2000. Acoustic measurement of intake and grazing behaviour of cattle. Grass Forage Sci., 55, 97-104.

Larson-Praplan S., George M.R., Buckhouse J.C. \& Laca E.A., 2015. Spatial and temporal domains of scale of grazing cattle. Anim. Prod. Sci., 55, 284-297.

Lawrence P.R. \& Becker K., 1997. The use of vibration analysis and telemetry to measure bite frequency and intensity in free-ranging horned ruminants. In: Proceedings of XVIII IGC Conference, 1997, Winnepeg, Manitoba, Canada, Session 5, 3-4.

Luginbuhl J.M., Pond K.R., Russ J.C.\& Burns J.C., 1987.A simple electronic device and computer interface system for monitoring chewing behavior of stall-fed ruminant animals. J. Dairy Sci., 70, 1307-1312.

Mangweth G. et al., 2012. Lameness detection in cows by accelerometric measurement of motion at walk. Berl. Munch. Tierarztl. Wochenschr., 125(9-10), 386396.

Martiskainen P. et al., 2009. Cow behaviour pattern recognition using a three-dimensional accelerometer and support vector machines. Appl. Anim. Behav. Sci., 119(1-2), 32-38.

Milone D.H. et al., 2012. Automatic recognition of ingestive sounds of cattle based on hidden Markov models. Comput. Electron. Agric., 87, 51-55.

Nadin L.B. et al., 2012. Comparison of methods to quantify the number of bites in calves grazing winter oats with different sward heights. Appl. Anim. Behav. Sci., 139(12), 50-57.

Navon S., Mizrach A., Hetzroni A. \& Ungar E.D., 2013. Automatic recognition of jaw movements in free-ranging cattle, goats and sheep, using acoustic monitoring. Biosyst. Eng., 114(4), 474-483.

Nydegger F., Gygax L. \& Egli W., 2010. Automatic measurement of rumination and feeding activity using a pressure sensor. In: International Conference on Agricultural Engineering-AgEng 2010: towards environmental technologies, 6-8 September 2010, Clermont-Ferrand, France. Cemagref.

O’Driscoll K., O’Brien B., Gleeson D. \& Boyle L., 2010. Milking frequency and nutritional level affect grazing behaviour of dairy cows: a case study. Appl. Anim. Behav. Sci., 122(2-4), 77-83.

Oudshoorn F.W. et al., 2013a. Estimation of grass intake on pasture for dairy cows using tightly and loosely mounted di- and tri-axial accelerometers combined with bite count. Comput. Electron. Agric., 99, 227-235.
Oudshoorn F.W. \& Jorgensen O., 2013b. Registration of cow bites based on three-axis accelerometer data. In: Berckmans D. Proceedings of the $6^{\text {th }}$ European Conference on Precision Livestock Farming, Precision Livestock Farming '13, 10-12 September 2013, Leuven, Belgium, 771-777.

Pahl C. et al., 2015. Suitability of feeding and chewing time for estimation of feed intake in dairy cows. Animal, doi: $10.1017 /$ S 1751731115001366

Penning P.D., 1983. A technique to record automatically some aspects of grazing and ruminating behaviour in sheep. Grass Forage Sci., 38(2), 86-96.

Rook A.J., Huckle C.A. \& Penning P.D., 1994. Effects of sward height and concentrate supplementation on the ingestive behaviour of spring-calving dairy cows grazing grass-clover swards. Appl. Anim. Behav. Sci., 40(2), 101-112.

Ruckebusch Y., Bueno L. \& Latour A., 1973. Un dispositif simple et autonome d'enregistrement de l'activité alimentaire chez les bovins au pâturage. Ann. Rech. Vet., 4, 627-636.

Rus M.A., Wobschall A., Storm S. \& Kaufmann O., 2013. DairyCheck - a sensor system for monitoring and analysis of the chewing activity of dairy cows. Landtechnik, 68(6), 395-398.

Rutter S.M., 2000. Graze: a program to analyze recordings of the jaw movements of ruminants. Behav. Res. Meth. Instrum. Comput., 32(1), 86-92.

Rutter S.M., Champion R.A. \& Penning P.D., 1997. An automatic system to record foraging behaviour in freeranging ruminants. Appl. Anim. Behav. Sci., 54, 185-195.

Schlecht E., Hülsebusch C., Mahler F. \& Becker K., 2004. The use of differentially corrected global positioning system to monitor activities of cattle at pasture. Appl. Anim. Behav. Sci., 85(3-4), 185-202.

Stobbs H.T. \& Cowper L.J., 1972. Automatic measurement of the jaw movements of dairy cows during grazing and rumination. Trop. Grasslands, 6(2), 107-112.

Tani Y., Yokota Y., Yayota M. \& Ohtani S., 2013. Automatic recognition and classification of cattle chewing activity by an acoustic monitoring method with a single-axis acceleration sensor. Comput. Electron. Agric., 92, 5465.

Umemura K., Wanaka T. \& Ueno T., 2009. Technical note: estimation of feed intake while grazing using a wireless system requiring no halter. J. Dairy Sci., 92(3), 9961000 .

Ungar E.D. et al., 2006a. The implications of compound chew-bite jaw movements for bite rate in grazing cattle. Appl. Anim. Behav. Sci., 98(3-4), 183-195.

Ungar E.D. \& Rutter S.M., 2006b. Classifying cattle jaw movements: comparing IGER Behaviour Recorder and acoustic techniques. Appl. Anim. Behav. Sci., 98(1-2), 11-27.

Ungar E.D., Blankman J. \& Mizrach A., 2007. The classification of herbivore jaw movements using 
acoustic analysis. In: Cox S., 2007. Proceedings of the $3^{\text {rd }}$ European Conference on Precision Livestock Farming, Precision Livestock Farming '07, 3-7 June 2007, Skiathos, Greece, 79-85.

Vallentine J.F., 2000. Grazing management. Amsterdam, The Netherlands: Elsevier.
Walker S.L. et al., 2008. Lameness, activity time-budgets, and estrus expression in dairy cattle. J. Dairy Sci., 91(12), 4552-4559.

(64 ref.) 